\title{
MAPPING QTLS ASSOCIATED WITH ROOT TRAITS RELATED TO DROUGHT RESISTANCE IN VIETNAMESE UPLAND RICE
}

\author{
Nguyen Duc Thanh", Nguyen Thi Kim Lien, Pham Quang Chung, \\ Tran Quoc Trong, Le Thi Bich Thuy, and Henry Nguyen
}

Plant Cell Genetics Laboratory, Institute of Biotechnology,

Vietnamese Academy of Science and Technology, 18 Hoang Quoc Viet, Cau Giay, Hanoi, Vietnam

Received 15 May 2006

\begin{abstract}
Upland rice grows on 19 million ha, about $15 \%$ of the world's rice plantation [2]. The production of upland rice is crucial to agricultural economy of many countries [15]. The yield of upland rice is very low with an average of about $1 \mathrm{t} / \mathrm{ha}$. Drought is a major constraint to the productivity of upland rice. In this paper, we present the results on mapping QTLs for root traits related to drought resistance (maximum root length, root thickness, root weight to shoot and deep root weight to shoot ratios) in upland rice using a recombinant inbreed (RI) population derived from a cross between Vietnamese upland rice accessions. The first molecular linked of Vietnamese upland rice were constructed. The map consists of 239 markers (36 SSR and 203 AFLP markers) mapped to all 12 rice chromosomes. This map covered $3973.1 \mathrm{cM}$ of rice genome with an average distance of $16.62 \mathrm{cM}$ between the markers. Twenty three putative QTLs were detected. Among them, four QTLs for MRL, four QTLs for R/SR, four QTLs for DR/SR, two QTL for RN, two QTLs for RT, two for PH, and five QTLs for TN were recorded. There are several SSR markers such as RM250, RM270, RM263, RM242, RM221 linked to QTL regions. They could be very useful for drought resistant selection in rice. Some common QTLs for maximum root length and deep root weight to shoot ratio were observed in different genetic background (RDB09 $\times$ R2021 and IR64 $\times$ Azorean populations) and ecological locations (IRRI and Vietnam). These QTLs could be very useful for precise locating drought resistant gene(s) and marker-assisted selection.
\end{abstract}

\section{INTRODUCTION}

Upland rice grows on 19 million ha, about $15 \%$ of the world's rice plantation [2]. The production of upland rice is crucial to agricultural economy of many countries [15]. The yield of upland rice is very low with an average of about $1 \mathrm{t} / \mathrm{ha}$. Drought is a major constraint to the productivity of upland rice.

Drought resistance is a complex trait influenced by four general physiological mechanisms: Escape, avoidance, tolerance, and recovery $[4,5,8,13]$. In upland rice root thickness, deep rooting, and root/shoot ratio are considered as the most important root traits for drought resistance [21].

\footnotetext{
*Corresponding author e-mail: pcg-ibt@hn.vnn.vn
} 
The use of molecular markers (DNA markers) provides a more effective selection technique for crop improvement and has an advantage over selection based on phenotype [5, 10]. Amplified fragment length polymorphism (AFLP), and microsatellite or simple sequence repeat (SSR) are PCR-based markers and proved to be very powerful tools for investigating genetic relationships between plant species and genetic mapping.

Mapping QTLs for drought escape and tolerance using a set of random introgression lines of rice was recently reported [19]. Mapping genes controlling root morphology and root distribution in upland rice have been reported in a doubled-haploid population derived from an indica $\times$ japonica cross using RFLP markers [20]. QTLs for root growth and root penetration ability in upland rice also mapped in a F2 population derived from a cross between drought resistant varieties Bala and Azucena using RFLP and AFLP markers [10, 11].

In this paper, we present the results on mapping QTLs for root traits related to drought resistance (maximum root length, root thickness, root weight to shoot and deep root weight to shoot ratios) in upland rice using a recombinant inbreed (RI) population derived from a cross between Vietnamese upland rice accessions (one of which belong to japonica subspecies, another is indica once), and SSR and AFLP markers.

\section{MATERIALS AND METHODS}

\subsection{Materials}

A population of $135 \mathrm{RI}$ lines derived from a F6 progenies of a cross between two upland rice, one belong to japonica subspecies RDB09 and another belong to indica subspecies R2021 was used in this study. Both parents of the cross are Vietnamese local accessions.

\subsection{Evaluation of root traits}

Maximum root length (MRL), root thickness (RT), root numbers (RN), root weight to shoot ratio $(\mathrm{R} / \mathrm{SR})$ and deep root weight to shoot ratio (DR/SR) were analyzed at Institute of Biotechnology, Hanoi. The upland rices were grown in plastic tubes (one plant/tube) with $16 \mathrm{~cm}$ in diameter and $1 \mathrm{~m}$ in height and with hole for drainage. The RI lines were evaluated in completely randomized design three replications of one plant per line. The samplings were taken at 45 days after sowing. In addition, the measurement of shoot traits like tiller number (TN) and plant height (PH) were also taken for investigation of relationship between root and shoot parameters.

\subsection{DNA isolation}

Genomic DNA was isolated from $0.5-1 \mathrm{~g}$ of leave of the upland rice lines using CTAB method described by Saghai Maroof et al., 1994 [8] with minor modification: DNA extraction by $1 \%$ Cetyltrimetylammonium bromide (CTAB) solution in $100 \mathrm{mM}$ Tris, $500 \mathrm{mM} \mathrm{NaCl}$ and $50 \mathrm{mM}$ EDTA. The crude DNA obtained after purification using chloroform: isoamylalcohol was dissolved in 500 to $1000 \mu \mathrm{l}$ of TE buffer. After RNase treatment ( $5 \mu \mathrm{lof} 10 \mathrm{mg} / \mathrm{ml}$ solution) for $30 \mathrm{~min}$ at $\left.37^{\circ} \mathrm{C}\right)$, the DNA was then purified by phenol: chloroform: isoamylalcohol (25:24:1).

\subsection{SSR analysis}

A total of 128 SSR primers (Research Genetics inc. USA) were screened with parental lines to determine polymorphism between the parents. PCR reactions with SSR primers were performed 
in a volume of $20 \mu \mathrm{l}$ containing $2 \mu \mathrm{l}$ PCR buffer, $15 \mathrm{mM} \mathrm{MgCl}_{2}, 0.4 \mu \mathrm{l}$ of $10 \mu \mathrm{M}$ each primer $05 \mu \mathrm{l}$ Tag polymerase $(5 \mathrm{U} / \mu \mathrm{l})$ and $50 \mathrm{ng}$ DNA. PCR reactions were performed on MJ PCR machine (MJ Research, Inc., USA) with PCR profile: $94^{\circ} \mathrm{C}$ in $5 \mathrm{~min}, 35$ cycles of $94^{\circ} \mathrm{C}$ in $1 \mathrm{~min}$, $55^{\circ} \mathrm{C}$ in $1 \mathrm{~min}$ and $72^{\circ} \mathrm{C}$ in $2 \mathrm{~min}$. The final extension was kept $7 \mathrm{~min}$ at $72^{\circ} \mathrm{C}$. The PCR products were electrophoresed using $4 \%$ of denaturing polyacrylamide gels. After electrophoresis, gels were stained with silver nitrate. For silver staining, the gels were fixed in fix/stop solution (10\% acetic acid) for $30 \mathrm{~min}$. After washing the gels (3 times) with distilled water, the gels were stained in staining solution $(0.2 \%$ silver nitrate, $0.05 \%$ formaldehyde) for $30 \mathrm{~min}$ and then the gels were rinsed with distilled water in $10 \mathrm{sec}$ and transferred to prechilled $\left(4-10^{\circ} \mathrm{C}\right)$ developer solution $(3 \%$ sodium carbonate, $0.05 \%$ formaldehyde, $0.0002 \%$ sodium thiosulfate) until the bands are visible.

\subsection{AFLP analysis}

AFLP analysis was conducted at Plant Cell Genetics Laboratory, Institute of Biotechnology (IBT) according to Vos et al., 1995 [17]. The selective amplified fragments were separated using 5\% of denaturing polyacrylamide gels. Electrophoresis was carried at constant power 100 $\mathrm{W}$ for $2 \mathrm{~h}$. After electrophoresis, the gels were stained with silver nitrate.

\subsection{Map construction}

The linked map was constructed using Mapmaker 3.0 (Lander et al., 1987; Lincoln et al., 1990) with LOD score of 3.0 and 8.0, and recombination fraction of 0.4.

QTL map was constructed using Mapmaker/ QTL 1.1 Program (Lincoln et al., 1992).

\subsection{Statistical and QTL analysis}

Analyses of variance were performed to determine the genetic variation between lines of the RI population for all investigated traits using SAS program (SAS Institute, North California).

\subsection{QTL comparison}

The approximate common QTL regions for MRL and DR/SR, the most important root traits for drought resistance, in our RDB09 $\times$ R2021 population and IR64 $\times$ Azucena [20] population were compared using Temnykh's map [16] as intermediate map to locate approximate common chromosome regions.

\section{RESULTS}

\subsection{Construction of molecular linked map}

The preliminary map with 36 SSR markers and only 12 AFLP markers mapped on ten chromosome (chromosome 1, 1 marker; Chromosome 2, 1 marker; chromosome 3, 1 marker; chromosome 4, 1 marker; chromosome 5, 2 marker; chromosome 6, 1 marker; chromosome 7,1 marker; chromosome 8,1 marker; chromosome 11, 2 marker and chromosome 12,1 marker) covering $1499 \mathrm{cM}$ of rice genome was accomplished at the end of RF 96001 \#506; RF90075\#5 Project [7].

In this work, 191 AFLP markers were added to previous map and the present map consists of 239 markers (36 SSR and 203 AFLP markers) mapped to all 12 rice chromosomes. This map covered $3973.1 \mathrm{cM}$ of rice genome. The average distance between markers is $16.62 \mathrm{cM}$ (Fig. 1). 
Of 203 AFLP markers, 36 were mapped on chromosome 1, 12 on chromosome 2, 23 on chromosome 3, 9 on chromosome 4, 15 on chromosome 5, 23 on chromosome 6, 2 on chromosome 7,33 on chromosome 8,10 on chromosome 9, 13 on chromosome 10, 5 on chromosome 11, and 22 on chromosome 12.
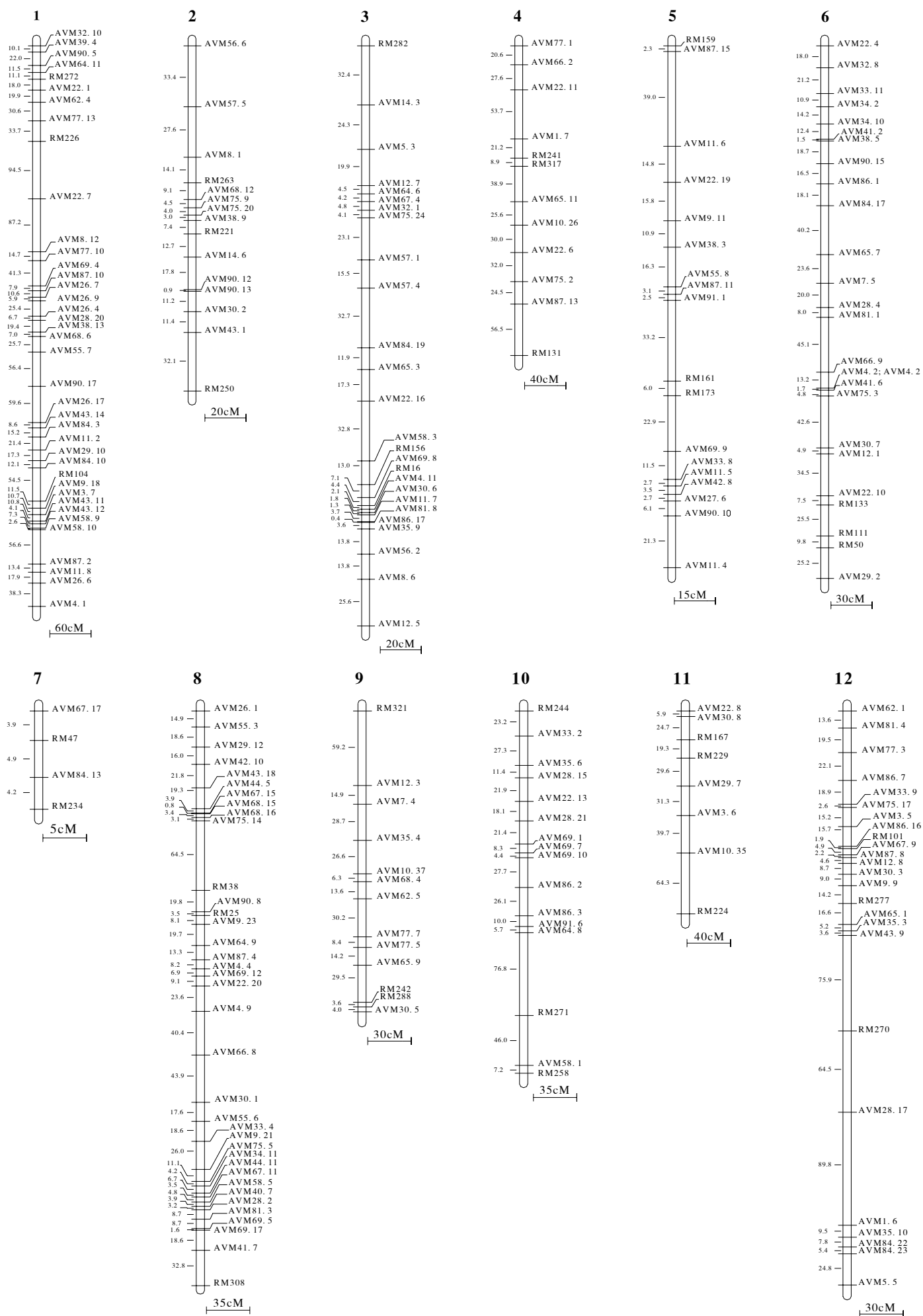

Fig. 1: A molecular linked map in upland rice using RDB09 $\times$ R2021 RI population 326 


\subsection{QTL analysis}

The QTL analysis was done for five root traits and two shoot traits using Mapmaker/QTL (version 1.1) software. A total 16 QTLs for root and 7 QTLs for shoot traits were identified (Table 1 and Fig. 2).

Table 1: QTLs for root and shoot traits as identified by interval mapping (MapMarker/QTL)

\begin{tabular}{llllllll}
\hline Trait & Interval & Chrom \# & Length $^{\mathrm{a}}$ & Position $^{\mathrm{b}}$ & $\begin{array}{l}\text { Variance } \\
(\%)^{\mathrm{c}}\end{array}$ & $\begin{array}{l}\text { Additive } \\
\text { effect }\end{array}$ & LOD $^{\mathrm{e}}$ \\
\hline Plant & AVM26.9-AVM26.4 & 1 & 25.4 & 25.0 & 9.7 & 11.423 & 2.12 \\
height & AVM9.18-AVM3.7 & 1 & 10.7 & 5.0 & 19.2 & 11.025 & 5.02 \\
\hline Tiller & AVM84.19-AVM65.3 & 3 & 12.0 & 5.0 & 11.3 & 1.0119 & 2.85 \\
number & AVM10.26-AVM22.6 & 4 & 30.0 & 25.0 & 23.3 & -1.8511 & 3.43 \\
& AVM87.13-RM131 & 4 & 56.5 & 10.0 & 14.8 & -1.3587 & 2.29 \\
& RM50-AVM29.2 & 6 & 25.2 & 10.0 & 34.7 & -2.5765 & 3.28 \\
& AVM3.5-AVM86.16 & 12 & 15.7 & 0.0 & 9.8 & 0.9658 & 3.01 \\
\hline Root & AVM65.11-AVM10.26 & 4 & 25.6 & 15.0 & 13.5 & 0.0702 & 2.28 \\
thickness & AVM75.2-AVM87.13 & 4 & 24.5 & 15.0 & 14.8 & 0.0738 & 2.76 \\
\hline Root & AVM22.7-AVM8.12 & 1 & 87.2 & 5.0 & 9.6 & 10.966 & 2.26 \\
number & AVM84.19-AVM65.3 & 3 & 12.0 & 5.0 & 13.0 & 11.709 & 3.29 \\
\hline Maximum & AVM43.1-RM250 & 2 & 32.1 & 30.0 & 8.5 & -4.2222 & 2.20 \\
root length & AVM56.2-AVM8.6 & 3 & 13.8 & 5.0 & 9.1 & 4.4586 & 2.28 \\
& AVM62.5-AVM77.7 & 9 & 30.2 & 0.0 & 12.1 & -5.0608 & 3.72 \\
& RM270-AVM28.17 & 12 & 64.5 & 0.0 & 7.2 & 3.7784 & 2.17 \\
\hline Root & AVM8.1-RM263 & 2 & 14.1 & 10.0 & 13.4 & -2.3027 & 3.24 \\
weight to & AVM42.10-AVM43.18 & 8 & 21.8 & 10.0 & 18.0 & 3.2824 & 2.78 \\
shoot ratio & AVM12.3-AVM7.4 & 9 & 14.9 & 0.0 & 10.5 & -2.0362 & 3.17 \\
& RM242-RM288 & 9 & 3.6 & 0.0 & 10.2 & -2.0394 & 3.12 \\
\hline Deep root & AVM38.9-RM221 & 2 & 7.4 & 5.0 & 16.1 & -0.4871 & 4.17 \\
weight to & AVM12.3-AVM7.4 & 9 & 14.9 & 0.0 & 8.9 & -0.3622 & 2.67 \\
shoot ratio & AVM62.5-AVM77.7 & 9 & 30.2 & 0.0 & 11.3 & -0.4192 & 3.44 \\
& AVM65.9-RM242 & 9 & 29.5 & 25.0 & 12.5 & -0.4331 & 3.13 \\
\hline
\end{tabular}

${ }^{\mathrm{a}}$ : Interval between the two flanking markers (cM) where QTL is located; ${ }^{\mathrm{b}}$ : QTL position from the first marker (cM); ${ }^{c}$ : Phenotypic variation explained by each QTL (\%); ${ }^{d}$ : Additive genetic effect and the negative sign meant that P2 allele reduced the trait; ${ }^{e}$ : Maximum likelihood LOD score for the individual QTL.

Two QTLs for root thickness (RT) were located on chromosome 4, one flanked by the AFLP markers (AVM65.11-AVM10.26) and the other flanked, also, by AFLP markers AVM75.2 and AVM87.13. These QTLs explained 13.5 to $14.8 \%$ of the phenotypic variation with low additive effect (0.07) from RDB09 parent.

Two QTLs for root numbers (RN) were identified, one located one chromosome 1 (AVM22.7AVM8.12), and the other located on chromosome 3 (AVM84.19-AVM65.3). Both QTLs have high additive effect from RDB09 parent. 
Four QTLs were identified for maximum root length (MRL). One QTL on chromosome 2 flanked by AFLP marker AVM43.1 and SSR marker RM250; two QTLs on chromosome 3 and chromosome 9 flanked by AFLP markers AVM56.2-AVM8.6 and AVM62.5-AVM77.7, respectively; the QTL on chromosome 12 flanked by SSR marker RM270 and AFLP marker AVM28.17. The positions of these QTLs are very close to the flanked markers $(2.1 \mathrm{cM}$ from RM250, $5 \mathrm{cM}$ from AVM56.2, $0 \mathrm{cM}$ from AVM62.5 and RM270).

For root weight to shoot ratio, there are four QTLs were located: two on chromosome 9, one on chromosome 2, and one on chromosome 8 . The explained per cent of phenotypic variation ranged from 8.2 to 18.0 . Most of the QTLs regions were very close to the flanked markers (4.1 cM from RM263, 0 cM from AVM12.3 and RM242).
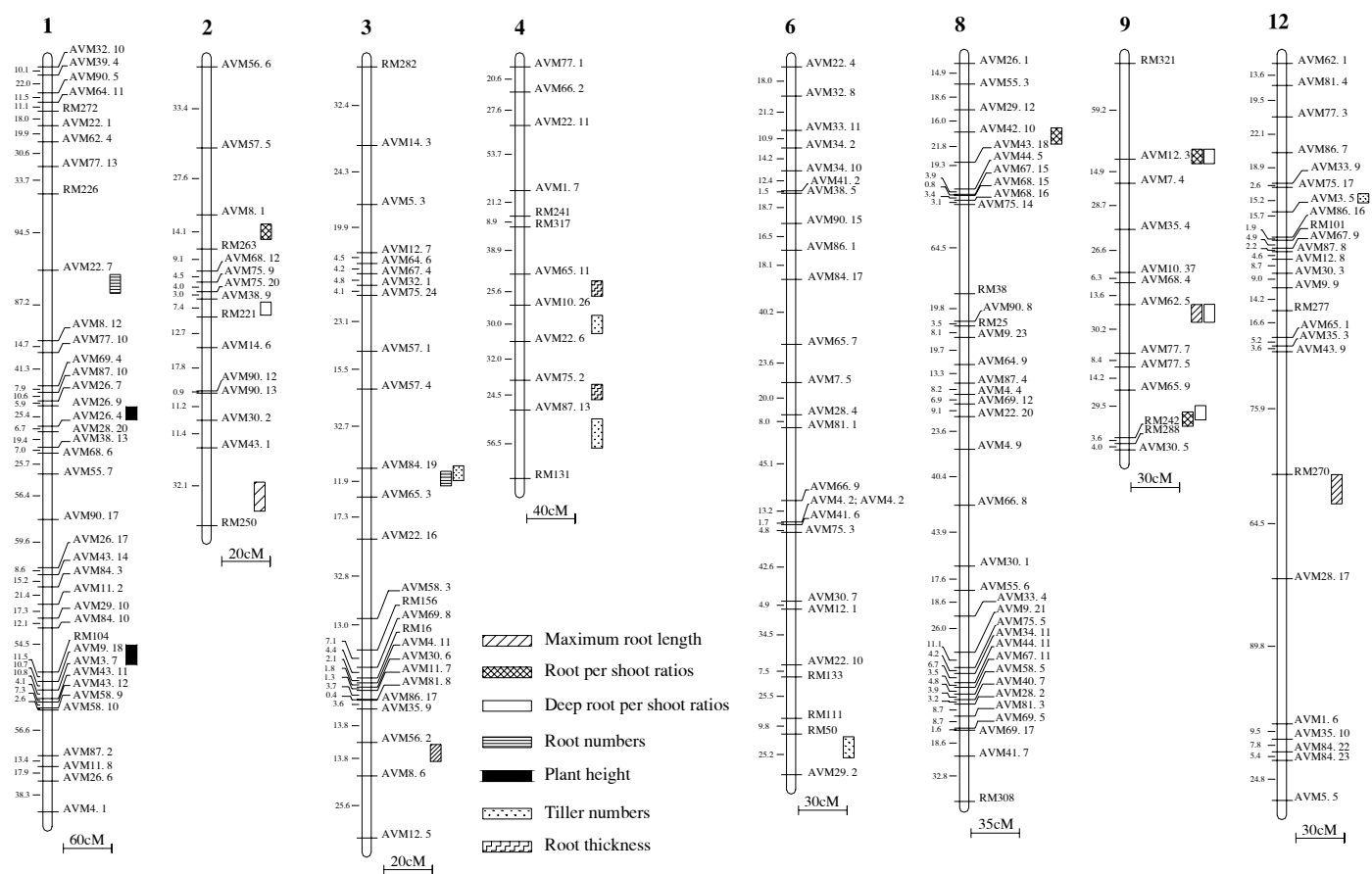

Fig. 2: A QTL map for root traits related to drought resistance in Vietnamese upland rice

Of four QTLs for deep root to shoot ratio, three QTLs (AVM12.3-AVM7.4; AVM62.5AVM77.7; AVM65.9-RM242) were located, one on chromosome 9 explained 8.9 to $12.5 \%$ of the phenotypic variation, and positioned close to AVM12.3, AVM62.5 and RM242. One QTL (AVM38.9-RM221) located at $2.4 \mathrm{cM}$ from RM221 marker on chromosome 2 and explained $16.1 \%$ of the phenotypic variation.

There were two common QTL regions for R/SR and DR/SR, one flanked AFLP markers AVM12.3 and AVM7.4, the other closed to SSR marker RM242. For MRL and DR/SR, there was, also, one common QTL region flanked to AFLP markers AVM62.5 and AVM77.7.

From obtained results, we found that there are several SSR markers such as RM250, RM270, RM263, RM242, RM221 could be very useful for drought resistant selection in rice. However, the further test needs to be carried out to confirm this.

In addition to QTLs for root traits, two QTLs for plant height $(\mathrm{PH})$ on chromosome 1 and five QTLs for tiller numbers (TN) were, also, identified. Among the QTL for TN, the regions flanked by AVM84.19-AVM65.3 on Chromosome 3, AVM10.26-AVM22.6 on chromosome 4, RM50-AVM29.2 on chromosome 6, and AVM3.5-AVM86.16 on chromosome 12 were 
positioned not far from the flanked markers $(5 \mathrm{cM}$ and lest $)$.

\subsection{Comparison of QTLs for maximum root length and deep root per shoot ratio detected in RDB09 $\times$ R2021 and IR64 × Azucena}

Yadav et al., 1997 [20] used a DH population of 105 lines derived from a cross between IR64 (irrigated indica) and Azucena (upland japonica) and identified some QTL regions for maximum root length (MRL) and deep root to shoot ratio (DR/SR) on chromosome 1, 2, 5, 6, 7, 8, and 9. In our work with RI population of 135 lines derived from a cross between RDB09 (upland japonica) and R2021 (upland indica), the QTLs for MRL were located on chromosome 2, 3, 9, and 12; the QTLs for DR/SR were located only on chromosome 2 and chromosome 9. There are three common regions for MRL on chromosome 3,9 and 12. The common regions on chromosome 3 flanked by CDO87 marker (in IR64 $\times$ Azucena population), and AVM56.2AVM8 (in RDB09 $\times$ R2021 population), these regions located bellow marker RM16. On chromosome 9, the common QTL regions for MRL located near RZ12 marker (in IR64 $\times$ Azucena population), and AVM62.5 (in RDB09 × R2021) flanked by RM242 and RM288 markers. On chromosome 12, the region between RG341 and RG958 (in IR64 × Azucena population) and region near to RM270 (in RDB09 $\times$ R2021) are common QTL regions for MRL. For DR/SR, there are common QTL regions on chromosome 2, these regions flanked by PALI-RZ58 and AVM38.9-RM221 markers, respectively. (Fig. 3, Table 2.).
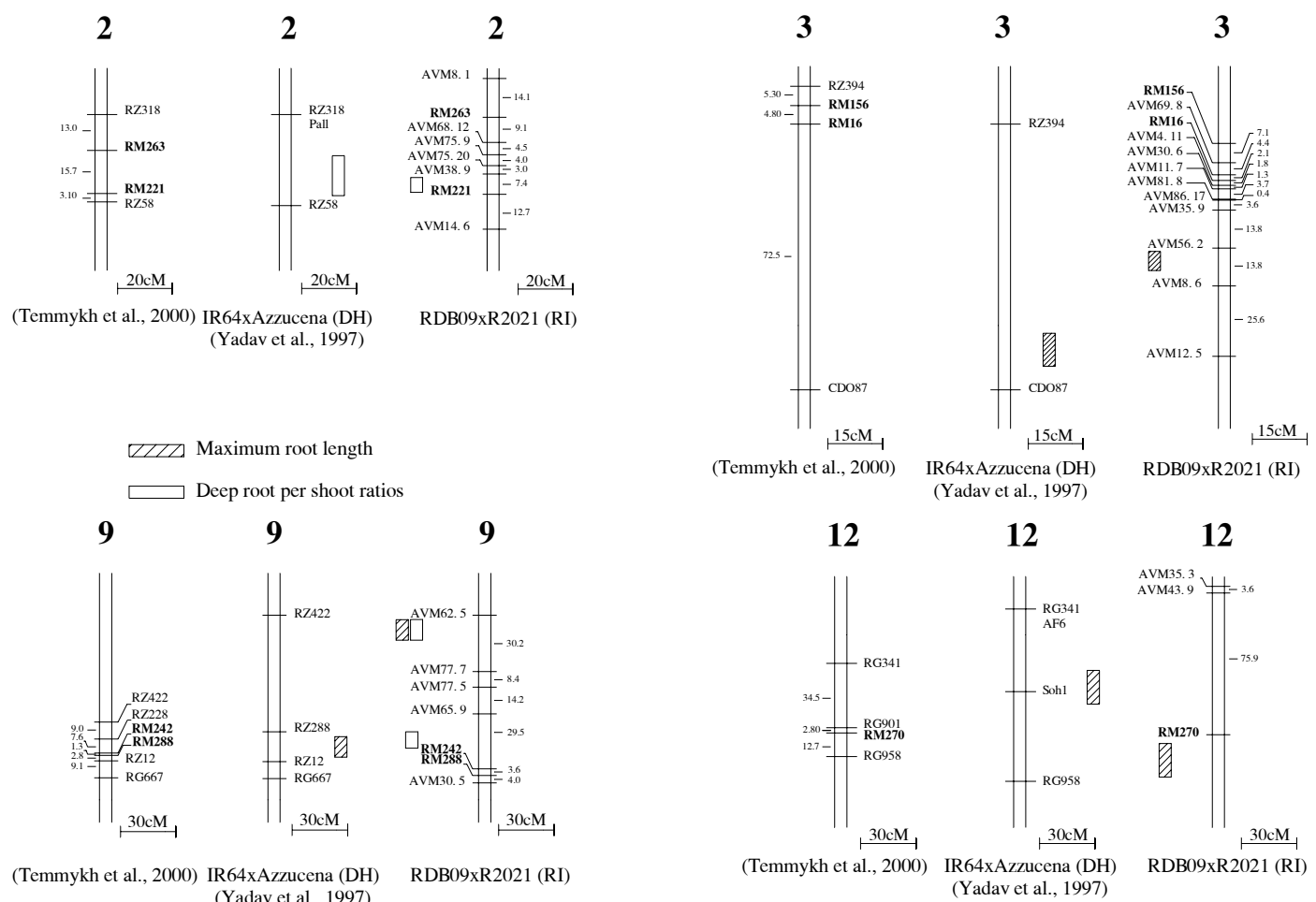

$$
\begin{aligned}
& \text { WII Maximum root length } \\
& \square \text { Deep root per shoot ratios }
\end{aligned}
$$

Fig. 3: Comparison of common QTL for maximum root length and deep root to root ratio with IR64 × Azuzucena DH population 
Table 2: Common QTLs in RDB09 × R2021 and IR64 × Azucena

\begin{tabular}{|c|c|c|c|c|c|c|}
\hline \multirow{2}{*}{ Trait } & \multirow{2}{*}{$\begin{array}{l}\text { Common } \\
\text { QTL }\end{array}$} & \multicolumn{5}{|c|}{ Chromosome Location of common QTL } \\
\hline & & Chr. & $\mathrm{RDB} 09 \times \mathrm{R} 2021$ & $\%$ Var. & IR64 × Azucena & $\%$ Var. \\
\hline \multirow{3}{*}{ MRL } & \multirow{3}{*}{3} & 3 & AVM56.2-AVM8.6 & 9.1 & PGI-1-CDO87 & $?$ \\
\hline & & 9 & AVM62.5-AVM77.7 & 12.1 & RZ12-RG667 & 9.0 \\
\hline & & 12 & RM270-AVM28.17 & 7.2 & RG958-RG341 & $?$ \\
\hline$\overline{\mathrm{DR} / \mathrm{SR}}$ & 1 & 2 & AVM38.9-RM221 & 16.1 & PALI-RZ58 & $?$ \\
\hline
\end{tabular}

The percentage of phenotypic variance explained by the common QTLs rather high (12.1 to 16.1). Thus, these common QTLs observed in different genetic background and ecological locations could be very useful for precise locating drought resistant gene(s) and marker-assisted selection.

In our map, there are several root QTLs flanked with SSR markers such as RM250, RM270 (for MRL), RM263, RM242, RM288 (R/SR), and RM221, RM242 (for DR/RS), these SSR makers could, also, be useful for marker-assisted drought selection.

\section{DISCUSSION}

Genetic map provides a mean for studying the genes controlling a trait, the location of genes along the chromosomes and the effects of variation in gene expression on the trait, the evaluation of genes regulating phenotype in different populations. Genetic mapping provides the information for map-based cloning of genes and marker-assisted selection. The molecular linked map is a map of chromosome showing distance between molecular markers (DNA markers) based on genetic recombination distances between them. The first molecular linked map of rice was reported by McCouch and coworkers using restriction fragment length polymorphic markers (RFLP) [6]. The QTL map is the map showing the linkage between a quantitative trait loci and genetic markers. This map provides the basis tools for the study of the variation underlying quantitative traits. QTL map of drought escape and tolerance in rice was recently reported [19]. Mapping genes controlling root morphology and root distribution in upland rice have also been reported [20]. We report here the first molecular linked map and QTL map for root traits related to drought resistance in Vietnamese upland rice. The map consists of 239 markers (36 SSR and 203 AFLP markers) mapped to all 12 chromosomes. This map covered $3973.1 \mathrm{cM}$ of rice genome with an average distance of $16.62 \mathrm{cM}$ between the markers. Twenty three putative QTLs were detected. Among them, four QTLs for MRL, four QTLs for R/SR, four QTLs for DR/SR, two QTL for RN, two QTLs for RT, two for plant PH, and five QTLs for $\mathrm{TN}$ were recorded.

AFLP markers are highly reproductive and give high level of polymorphism, therefore they are increasingly using in the construction of linkage maps. The disadvantage of the AFLP markers is that once a marker identified to be linked with a trait it needs to be converted to an easy usable PCR marker for marker-assisted selection such as sequence tagged site (STS) or sequence-characterized amplified region (SCAR). In our map, along with AFLP markers we have used several SSR markers. There are several SSR markers such as RM250, RM270, RM263, RM242, RM221 linked to QTL regions. These markers could be very useful for drought resistant selection in rice, as they are ready to use without any conversion.

The common QTLs found in different populations and different environments are very useful in term of basic research and practical application, in particular, for marker-assited-seletion. The common QTLs for root penetration index (RPI) were identified in two populations R64 + Azucena [22] and IR58821 + IR52561 [1], the common QTLs for MRL were found in Azucena + Bala F2 population [11] and IRAT109 + Yuefu double haploid population [3]. Three common 
QTL regions for RN have also been found in CO39 + Moroberekan [18] and IRAT109 + Yuefu [3]. In the present work, we have, also, identified some common QTLs for MRL (AVM56.2AVM8.6, AVM62.5-AVM77.7, RM270-AVM28.17) and DR/SR (AVM38.9-RM221), on similar regions of different genetic background $($ RDB09 $\times$ R2021 and IR64 $\times$ Azucena populations) and ecological locations (IRRI and Vietnam). These QTLs could be very useful for precise locating drought resistant gene(s) and marker-assisted selection.

\section{ACKNOWLEDGEMENTS}

The work was supported by Rockefeller Foundation Grants \# 2001 FS 164. Our thanks are also extended to Dr. John O'Toole for his continued support, Mrs. Rita Harris for her coordination of the project, Dr. Brigitte Courtois and Mr. Modesto Amante for advance of RI population, Dr. Luu Ngoc Trinh for providing upland rice accessions.

\section{REFERENCES}

1. Ali, L. (1999), Mapping quantitative trait loci for root traits related to drought resistance in rice (Oryza sativa L.) using AFLP markers. Ph.D. dissertation, Taxas Tech University, Lubbock, Texas, USA.

2. Chang, T.T. and Loresto, G.C. (1986), Germplasm resources and breeding for drought resistance. Progress in upland rice research, Proceeding of the 1985 Jakarta Conference. IRRI, Los Banos, Philippine, pp. 199-212.

3. Li, Z., Mu, P., Li, C., Zhang, H., Li, Z., Gao, Y., and Wang, X. (2005), QTL mapping of root traits in double haploid population from a cross between upland and lowland japonica rice in three environments. Theor. Appl. Genet, vol. 110, pp. 1244-1255.

4. Loresto, G.C., Chang, T.T., and Tagumpay, O. (1976), Field evaluation and breeding for drought resistance. Philippine J. Crop Sci., vol. 1, pp. 36-39.

5. Ludlow, M.M., Chu, A.C.P., Clement R.J., and Kerslake, R.G. (1983), Adaptation of species of Centrocema to water stress. Aus. J. Plant Physiol., vol. 10, p. 119.

6. McCouch, S.R., Kochert, G., Yu, Z.H., Wang, Z.Y., Khush, G.S., Coffman, W.R., and Tanksley, S.D. (1988), Molecular mapping of rice chromosomes. Theor. Appl. Genet., vol. 76 , pp. 815-829.

7. Nguyen Duc Thanh, Phan Thi Bay, Dao Xuan Hai, Nguyen Thi Kim Lien, Quach Thi Lien, Tran Quoc Trong, Le Thi Bich Thuy, Le Tran Binh, and Le Thi Muoi (2003), Final Research Report Project No. RF 96001 \#506; RF90075\#5.

8. O'Toole, J.C. and Chang, T.T. (1979), Drought resistance in cereal-rice: A case study. In stress physiology of crop plants, Mussel H. and Staples R.C., eds. Wiley Interscience, New York, pp. 374-405.

9. Paterson, A.H., Tanksley, S.D. and Sorrells (1991), DNA markers in plant improvement. Adv. Agronomy, vol. 46, pp. 39-90.

10. Price, A.H., Steele, K.A., Moore, B.J., Barraclough, P.P., and Clark, L.J. (2000), A combined RFLP and AFLP linkage map of upland rice (Oryza sativa L.) used to identify QTLs for root - penetration ability. Theor Appl Genet., vol. 100(1), pp. 49-56.

11. Price, A.H. and Tomos, A.D. (1997), Genetic dissection of root growth in rice (Oryza sativa L.). II. Mapping quantitative trait loci using molecular markers. Theor. Appl. Genet, vol. 95, pp. 143-152. 
12. Saghai Maroof, M.A., Biyashev, R.M., Yang, G.P., Zhang, Q., and Allard, R.W. (1994), Extraordinarily polymorphic microsatellite DNA in barley: Species diversity, chromosome location, and population dynamics. Proc. Natl. Acad. Sci., USA, vol. 91, pp. 5466-5470.

13. Sullivan, C.Y.F., Yoshikawa, F., Eastin, J.D., Ross, W.M., Clegg, M.D., Maranville, J.W., and Hollister, A.L. (1971), Sorghum drought and heat resistance. In research in physiology of yield and management of sorghum in relation of genetic improvement. Ann. Report No5. University of Nebraska, pp. 9-23.

14. Tanksley, S.D., Young, A.H., Paterson, A.H., and Bonierbale (1989), RFLP mapping in plant breeding new tools for an old science. Biotechnology, vol. 7, pp. 257-264.

15. Tran Tuan Dat (1986), An overview of upland rice in the world. Progress in upland rice research, proceeding of the 1985 Jakarta Conference. IRRI, Los Banos, Philippine, pp. 5166.

16. Temnykh, S., Park, W.D., Ayres, N., Cartinhour, S., Hauck, N., Lipovich, L., Cho, Y.G., Ishi, T., and McCouch, S.R. (2000), Mapping and genome organization of microsatellite sequence in rice (Oryza sativa L.). Theor. Appl. Genet., vol. 100, pp. 697-712.

17. Vos, P., Bleeker, M., Reijans, M., Lee, T.V.D., Hornes, M., Frijters, A., Pot, J., Peleman, J., Kuiper, M., and Zabeau, M. (1995), AFLP: a new technique for DNA fingerpringting. Nucleic Acids Research., vol. 23, pp. 4407-4414.

18. Ray, J.D., Yu, L., McCouch, S.R., Champoux, M.C., Wang, G., and Nguyen, H.T. (1996), Mapping quantitative trait loci associated with penetration ability in rice (Oryza sativa L.). Theor. Appl. Genet, vol. 92, pp. 627-636.

19. Xu, J.L., Lafitte, H.R., Gao, Y.M., Fu, B.Y., Torres, R., and Li, Z.K., (2005), QTLs for drought escape and tolerance identified in a set of randon introgression lines of rice. Theor. Appl. Genet., vol. 111, pp. 1642-1650.

20. Yadav, R., Courtois, B., Huang, N., and Mclaren, G. (1997), Mapping genes controlling root morphology and root distribution in a doubled- haploid population of rice. Theor. Appl. Genet., vol. 94, pp. 610-632.

21. Yoshida, S. and Hasegawa (1982), The rice root system: Its development and function. Drought resistance in crops with emphasis on rice, IRRI, pp. 87-114.

22. Zheng, H.G., Pathan, M.S., Chandra Babu, R., Ali, L., Huang, N., Courtois, B., and Nguyen H.T. (1996), Molecular mapping of QTLs associated with root penetrartion ability in rice. Plant Genome IV. The International Conference on the Statua of Plant Genome research. Sandego, Calif. Abstract \# 125. 